\title{
ANÁLISE SOCIOAMBIENTAL DA SUB-BACIA 02 DO ARROIO OLARIAS DO MUNICÍPIO DE PONTA GROSSA - PR, COM O USO DAS GEOTECNOLOGIAS
}

\author{
SOCIO ENVIRONMENTAL ANALYSIS OF THE SUB-BASIN O2 OF THE \\ OLARIAS STREAM IN THE CITY OF PONTA GROSSA - PR, WICH THE \\ USE OF GEOTECHNOLOGY
}

\section{ANALYSE SOCIOENVIRONMENTALE DU SUB-VERSSANT O2 DU LAC OLARIAS DANS LA VILLE DE PONTA GROSSA - PR, AVEC L'UTILISATION DE GÉOTECHNIQUE}

\author{
Sérgio Ricardo Rogalski \\ Mestre em Geografia pela Universidade Estadual de Ponta Grossa. \\ Av. Carlos Cavalcanti, 4748 - CIPP Sala LP 111 - Campus Uvaranas \\ CEP: 84030-000 - Ponta Grossa/PR \\ E-mail: sergiorogalski@yahoo.com.br
}

\section{Everaldo Skalinski Ferreira}

Doutorando em Geografia pela Universidade de Brasília. Mestre em Geografia pela Universidade Estadual de Ponta Grossa. Professor adjunto do Centro Superior de Ensino dos Campos Gerais (CESCAGE). SGAN 912, MD C, BL I 218. Cep. 70790-120 Brasília DF E-mail: eskalinski@yahoo.com.br

\section{Resumo}

A disponibilidade de informações atualizadas e de fácil tratamento é condição primeira à gestão ambiental, o que pode ser conseguido com o uso das geotecnologias. Assim, neste artigo trata-se do uso das geotecnologias na análise e diagnóstico da emissão dos efluentes domésticos na sub-bacia 02 da bacia hidrográfica do arroio Olarias no município de Ponta Grossa - PR. Ponta Grossa possui um relevo bastante peculiar, onde o centro da cidade situa-se sobre um espigão topográfico de onde partem diversas drenagens em direção aos bairros. Sendo o relevo bastante acidentado com ocupações irregulares em encostas íngremes e fundos de vale, agrava a deficiência no saneamento básico. Para tanto, o processo do diagnóstico das ligações irregulares de esgoto em galerias de águas pluviais e no arroio acontece através do Programa de Despoluição Ambiental da Agência Reguladora de Águas e Saneamento Básico do município. A aplicabilidade de geotecnologias na gestão pública torna-se cada vez mais imprescindível para tomada de decisão, planejamento e gestão dos instrumentos urbanos e ambientais.

Palavras chave: Geotecnologias, Saneamento Básico, Bacia hidrográfica, Diagnóstico 


\begin{abstract}
The disponibility of actualized and easy treated information is a primary condition to the ambiental gestation, which can be achieved with the use of geotechnology. So, in this article we treat the use of geotecnology in the analysis and diagnose of domestic effluents in the sub-basin 02 of the watershed of the Olarias strean in the city of Ponta Grossa - PR. Ponta Grossa has a very peculiar topography, where the center of the city is located in a spike of which leaves many drainage to the neighbors of the city. The unique topography and also the irregular habitations in steep slopes and valley bottom makes worse the basic sanitation problem. So, the diagnose of irregular sewag ligations in gallery rain waters and also in the strean happens through the Regulatory Agency for Water and Sanitation of Ponta Grossa Environmental Cleaning Program - ECP. The use of geotecnologies in the public gestation becomes each time more important to take good decisions and also contributes to the planning and gestation of urban and environmental tools.
\end{abstract}

Keywords: Geotecnologies, basic sanitation, watershed, diagnose

\title{
Resumé
}

La disponibilité de l'information actuel et de facile traitement est fournie première pour la gestion de l'environnement, qui peut être réalisée avec l'utilisation de geotechnologies. Ainsi, dans cet article nous utilisons des geotechnologies dans l'analyse et de diagnostic de la question des effluents domestiques dans le sous-bassin 02 du bassin versant Olarias dans la ville de Ponta Grossa-PR Ponta Grossa a un relief assez particulière, où le Centre de la ville se situe sur un éperon de dont les drains topographiques diverses vers les quartiers. Soulagement assez robuste avec des professions irrégulières sur les coteaux abrupts et des vallées, aggrave la défaillance de l'assainissement. À cette fin, le processus de diagnostic de connexions irrégulières dans les galeries des eaux usées et des eaux pluviales à Olarias se passe à travers le programme de la dépollution de l'organisme de réglementation environnementale pour l'eau et l'assainissement de la ville. L'applicabilité de la géotechnique en gestion publique devient de plus en plus essentielle pour la prise de décision, de planification et de gestion des instruments urbaines et environnementales.

Mots-Clé: geotechnologies, assainissement de base, basin versant, diagnostic

\section{Introdução}

Este artigo trata da análise socioambiental da sub-bacia 02 do arroio Olarias, localizado no perímetro urbano da cidade de Ponta Grossa - PR (Figura 1). Situada nos domínios do Segundo Planalto Paranaense, tem seu sítio urbano distribuído de maneira peculiar sobre um espigão topográfico, com colinas alongadas de topos e vertentes 
convexas, de onde parte um conjunto de numerosos canais de $1^{\mathrm{a}}$ e $2^{\mathrm{a}}$ ordens conforme hierarquização fluvial proposta por Strahler (1952).

As características topográficas da cidade de Ponta Grossa de certa forma têm influenciado de maneira a impedir a otimização do desenvolvimento urbano, principalmente no que diz respeito a implantação e expansão do saneamento básico, ou seja, a rede de distribuição de água e esgotamento doméstico. A geomorfologia local caracteriza-se pela presença de encostas declivosas (pontos com mais de 30\%) e um total de $170 \mathrm{~km}$ de arroio em áreas urbanas (NUCLEAM, 2001).

A área urbana tem enfrentado problemas relativos ao saneamento básico, uma vez que a rede coletora de esgoto doméstico é projetada e implantada segundo as condições e características topográficas. Essa realidade está relacionada tanto pela falta de integração urbana quanto pela ausência e inépcia de políticas para expansão urbana, desencadeando o crescimento da cidade para regiões periféricas encarecendo os serviços de infra-estrutura urbana.

De acordo com a Presidência da República mediante a Lei Federal 11.445 de 05 de janeiro de 2007 estabeleceu-se aos municípios a necessidade de criação de Agências Reguladoras Municipais, cujo um dos seus objetivos é o de gerir os recursos hídricos por meio da gestão integrada, buscando melhorar tanto os aspectos específicos de saneamento básico, para atingirem-se melhores condições de vida e saúde pública, quanto a outros aspectos socioambientais encontrados nas bacias hidrográficas na maioria dos municípios brasileiros.

Sendo assim, a administração municipal de Ponta Grossa, na gestão de 2004 a 2008, em consonância com a Legislação Federal, criou através da Lei Municipal n. ${ }^{\text {o }}$ 8.428 de 16 de janeiro de 2006, da Câmara de Vereadores, a sua Agência Reguladora de Águas e Saneamento (ARAS), voltada a fiscalizar e regularizar as ações pertinentes ao saneamento básico e ao meio ambiente no município de Ponta Grossa.

Das ações principais da referida agência destaca-se o Programa de Despoluição Ambiental (PDA), cujo objetivo geral é identificar as ligações irregulares de esgotos nas bacias hidrográficas e encaminhar relatórios a Vigilância Sanitária para regularização das mesmas. Cabe destacar que esse trabalho de vistorias técnicas deve ser embasado numa abordagem socioambiental segundo os parâmetros do Programa de Despoluição Ambiental de bacias Hidrográficas (PRODES) da Agência Nacional de Águas - ANA. 
A bacia hidrográfica do arroio Olarias foi priorizada pela gestão municipal a realizar o PDA para implantação de um lago recreativo e urbanístico, porém essa bacia apresenta-se degradada. Essa bacia está dividida em 14 sub-bacias conforme os critérios da Concessionária SANEPAR de acordo com o sistema coletor de esgoto. A sub-bacia 02, nas análises do PDA foi a que mais apresentou problemas relativos ao saneamento básico e socioambiental sendo, portanto o recorte escolhido para estudo.

Para esse trabalho, que inclui as vistorias técnicas e a análise da relação meio com a população, faz-se necessário à utilização das geotecnologias, para o armazenamento de dados, banco de dados georreferenciado e elaboração dos diversos mapas temáticos, indispensáveis à tomada de decisões de planejamento ambiental.

Assim, o uso do geoprocessamento possibilitou relacionar diferentes dados temáticos como: urbanização e feições geomorfológicas, informações importantes para o poder público em relação a investimentos ao saneamento básico e às possíveis soluções mitigadoras dos principais problemas socioambientais. $\mathrm{O}$ produto final desse trabalho, em primeira instância, tornou-se projeto piloto na aplicação para os próximos PDAs do município de Ponta Grossa, além de subsidiar melhorias na aplicação do Plano Diretor Urbano, dentro de uma abordagem integrada. 

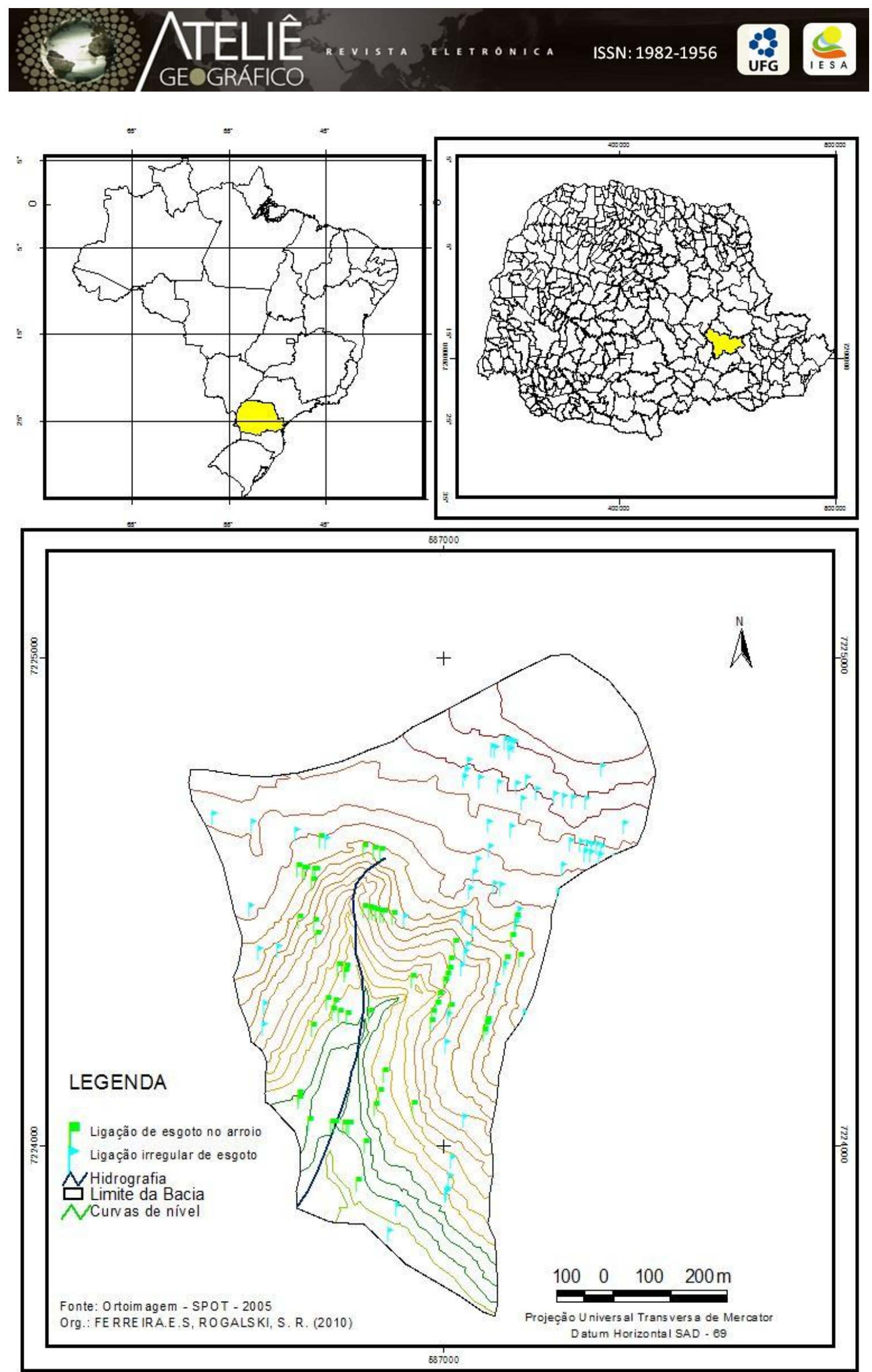

Figura 01 - Localização da sub-bacia 02 na bacia hidrográfica do arroio Olarias. 


\section{Abordagem socioambiental para gestão ambiental}

A gestão ambiental, tão necessária nestes tempos de crise ambiental, pode ser definida como um processo mais amplo de gestão do território, que visa implementar políticas integradas de transformação sócio-espacial e de regulação dos comportamentos individuais e coletivos. Segundo Pereira (2001) essa gestão refere-se à administração ou gerenciamento de planos e/ou diretrizes inerentes ao meio ambiente.

A disponibilidade de informações atualizadas e de fácil tratamento é condição primeira à gestão ambiental, por isso dentro dos recursos da área das geotecnologias, o uso do geoprocessamento, sensoriamento remoto e dos sistemas de informação geográfica (SIG) têm sido amplamente utilizados. Em outras palavras, apresentam-se como um instrumento fundamental para nortear o gerenciamento ambiental, pois, através de banco de dados temporais apresentam-se as informações necessárias em diferentes níveis para análise e tomada de decisão.

A implantação desse sistema de informação, em instituições privadas ou públicas e aplicada aos estudos de análise socioambiental, tem permitido realizar o diagnóstico das condições ambientais de um determinado local, bem como otimizar a compreensão das dinâmicas ambientais decorrentes da intervenção humana em ecossistemas naturais.

Nesse caso, para o processo de gestão urbana é imprescindível desenvolver uma visão moderna e integrada com a utilização das Geotecnologias, em especial quando se refere à infra-estrutura e às questões ambientais. A aplicabilidade desses instrumentos no tratamento do saneamento ambiental torna-se relevante principalmente para determinar os vetores para controle de saúde, bem como definir a drenagem urbana, uso da terra, conflitos ambientais e a relação socioambiental das bacias hidrográficas.

Nesse sentido, ao tratar de saneamento ambiental recomenda-se definir uma unidade espacial que favoreça e facilite tanto a obtenção quanto o tratamento dos dados e informações, por isso a opção pela unidade bacia hidrográfica, elevada à categoria de análise espacial. Sob um olhar geográfico apresenta-se a seguinte proposição, "a bacia hidrográfica como unidade de estudos pode ser considerada como a expressão, em diversas escalas, da interação da sociedade e natureza na produção do espaço" (CARVALHO, 2004, p. 36). 


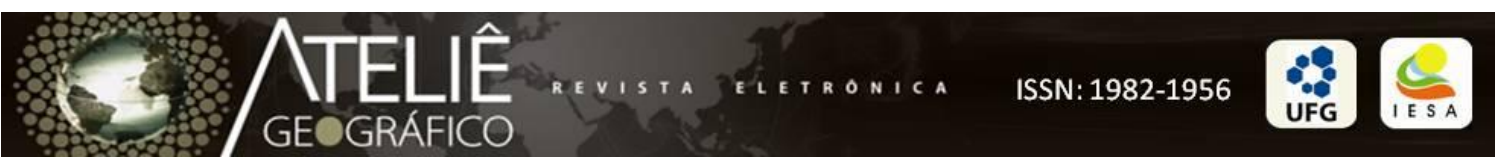

A degradação ambiental das bacias hidrográficas urbanas está relacionada ao processo histórico de urbanização dos municípios bem como à falta de políticas públicas associadas à ausência de gestão integrada dos atores sociais e políticos que utilizam e constroem o espaço urbano. Muitas vezes, também estabelecem conflitos e negligência dos preceitos fundamentais legais norteadores da política tanto para recursos hídricos quanto ao planejamento urbano (ROGALSKI; CARVALHO, 2010).

Desta forma, é necessário inserir na abordagem ambiental a perspectiva humana, ou seja, os elementos de caráter social, econômico, político e cultural (MENDONÇA, 2001). Sendo assim, o autor aponta que, “Observa-se assim, na atualidade, diante de tão importante desafio, uma forte tendência à utilização, de forma ampla, do termo socioambiental, pois se tornou muito difícil e insuficiente falar de meio ambiente somente do ponto de vista da natureza quando se pensa na problemática interação sociedade-natureza do presente, sobretudo no que concerne a países em estágio de desenvolvimento complexo" (MENDONÇA, 2002, p.117).

Enfim, com o novo paradigma referente ao processo de governança do território, a gestão pública e suas políticas de desenvolvimento econômico e social devem ser norteadas por uma perspectiva de um planejamento integrado, para que, através das interdisciplinaridades das ações e da participação dos diversos atores sociais, possam-se alcançar melhores condições e qualidade de vida a toda comunidade sem, entretanto, afetar o meio ambiente.

\section{Caracterização da área de estudo}

A área de estudo do presente artigo é a sub-bacia 02 da bacia hidrográfica do arroio Olarias compreendendo as vilas Princesa e Clóris, as quais não possuem rede coletora de esgoto. Embora o limite desta sub-bacia ultrapasse os limites urbanos definidos pelo município, faz-se necessário analisar a área da bacia hidrográfica do arroio Olarias em função da metodologia proposta.

O município de Ponta Grossa possui 12 pequenas bacias hidrográficas urbanas. Essa rede hidrográfica apresenta um padrão de drenagem radial, expressa pelos quatro (4) principais arroios - Arroio Olarias, Pilão de Pedra, Arroio da Ronda e Arroio da 
Madureira - cujas nascentes estão localizadas ou no centro comercial da cidade, ou próximo a ele e seguindo em diversas direções dentro do perímetro urbano.

O alto curso do arroio Olarias situa-se a partir da porção centro-sudeste da cidade de Ponta Grossa, estendendo-se para sul até onde se encontra com a margem direita Rio Cará-Cará (MELLO; GODOY, 1997). O arroio Olarias, quando deságua no Cará-Cará classifica-se como de $4^{\mathrm{a}}$ ordem e a sub-bacia 02 pertence a $2^{\mathrm{a}}$ ordem na classificação de rios (STRAHLER, 1952).

De acordo com Mello e Godoy (1997) as condições físico-naturais da área possui um substrato dominantemente constituído pela Formação Ponta Grossa, além de rochas intrusivas correlatas ao magnetismo Serra Geral e sedimentos quaternários, estes localizados nas planícies aluviais. Os solos aí encontrados são classificados como latossolos, cambissolos e hidromórficos gleyzados. Em sua maioria são argilosos, pois estão assentados sobre o folhelho da Formação Ponta Grossa, sendo que apenas uma pequena porção encontra-se sobre os diques e soleiras de diabásio (DIEDRICHS, 2001).

A área apresenta vertentes retilíneas - terço médio - enquanto as vertentes convexas aparecem, sobretudo, nas cabaceiras localizadas na porção norte da sub-bacia 01 e 02. Geomorfologicamente a área apresenta um forte controle estrutural e litológico, em decorrência da presença dos diques de diabásio que favorecem a presença de declividades mais acentuadas expressas pelas encostas íngremes. Ao longo dos canais fluviais de padrão dendrítico é comum a presença de cachoeiras e corredeiras, mais precisamente na porção superior da bacia hidrográfica do arroio Olarias (MELLO; GODOY, 1997).

Nesse ambiente físico-natural, a crescente expansão urbana, ocorre não só nas porções mais estáveis dos topos e terços superior e médio das vertentes, mas também nas planícies de inundações e fundos de vale. Isto é notório na área de estudo, onde as condições geológica-hidro-geomorfológicas são fatores limitantes para uma ocupação urbana com qualidade de vida.

\section{Material e métodos}

A sub-bacia-02 foi considerada pela ARAS como uma área que apresenta pressões ambientais significativas, neste sentido relevante para estudos socioambientais. 
Os parâmetros definidos para análise deste estudo foram: dados do PDA/ARAS e a metodologia do IDA proposto por Brandão (2005), cujo parâmetros são: declividade, solos, vegetação e pressão antrópica. A pressão antrópica enquanto um parâmetro de atividade humana é elencado no IDA para diferenciar outras metodologias que não levam em consideração essa realidade no diagnóstico ambiental de bacias hidrográficas, como por exemplo, de Ross (1994) e do Instituto Nacional de Pesquisas Espaciais INPE (1996).

O recorte espacial neste trabalho é a sub-bacia 02 da bacia hidrográfica Olarias, aqui uma pequena bacia urbana, porém importante por apresentar índices expressivos de ligações irregulares de esgoto doméstico, bem como problemas geoambientais, associados principalmente a declividade acentuada nas cabeceiras da bacia hidrográfica. Para se realizar a análise da realidade tempo-espacial, utilizou-se os recursos das geotecnologias.

A base cartográfica foi disponibilizada pelo laboratório de Geoprocessamento da Universidade Estadual de Ponta Grossa - UEPG com a obtenção do Mapa topográfico Folha de Ponta Grossa escala 1: 50.000, Ortoimagens do sensor SPOT 5, com resolução espacial de 5 metros cedido pelo Secretaria Estadual de Desenvolvimento Urbano do Paraná - Paranacidade.

Com o programa Envi 3.6 (Enviroment for Visualing Images) foram realizados o georreferenciamento e a correção geométrica do mapa topográfico, a partir da Folha SG 22-X-C-II/2 DSG, ano 1980. Com a obtenção da base cartográfica em formato digital, a qual foi armazenada no software Envi 3.6 e Arcview 3.2, foram digitalizadas as curvas de nível com eqüidistâncias de 10 metros, rede drenagem, limite da área de estudo. Após a aquisição desses dados a base foi armazenada e ajustada na ortoimagem do ano de 2005.

Dentro do programa Arcview 3.2, a partir das curvas de nível foi possível realizar o modelo digital do terreno (MDT), com finalidade de aperfeiçoar a interpretação e avaliação da influência dos condicionantes físico-naturais (topografia) e sua relação com o saneamento básico.

Para identificação dos pontos irregulares de esgoto nesta sub-bacia foram utilizados dados cadastrais dos imóveis vistoriados pelo Programa de Despoluição Ambiental - PDA da ARAS, que utilizou a técnica do lançamento de corante nas pias, 
ralos e vasos sanitários das residências. Outra etapa desse trabalho consistiu em georreferenciar os pontos irregulares e mapeá-los.

Cada ligação irregular foi registrada de acordo com as suas coordenadas geográficas, através do receptor Global Possitioning System (GPS), e pelas matrículas fornecidas da SANEPAR para o PDA de Olarias em frente aos imóveis que se encontrassem irregulares no sistema sanitário de esgoto.

Além disso, foi realizada a sistematização dos dados no programa Microsoft Office Excel 2003, para geração de gráficos e tabelas. A última etapa foi à geração do mapa das ligações irregulares onde foram espacializadas as irregularidades de esgoto nas vias públicas (galeria de águas pluviais) e arroio (fundos de vale). No programa ArcView 3.2 foi gerado um banco de dados contendo as seguintes informações: endereço, matrícula da SANEPAR, número da residência, nome do proprietário e tipo da irregularidade. Esse banco de dados permitiu o cruzamento das informações, gerando assim novos mapas temáticos e possibilitando análises para novas tomadas de decisão.

\section{Resultados e discussão}

A utilização do mapa topográfico Folha de Ponta Grossa escala 1: 50.000 e da Ortoimagem sensor SPOT 5 com resolução espacial de 5 metros permitiu o exame dos condicionantes do meio físico do recorte espacial deste trabalho. A visualização das feições geomorfológicas demonstra que as declividades das cabeceiras da bacia variam entre $20-45 \%$ cujas áreas são densamente urbanizadas o que favorece a riscos geoambientais, como deslizamentos. Essa área apresenta solos do tipo Cambissolos, estes com textura arenosa e que associados com declividades acentuadas e ausência de cobertura vegetal propiciam o carreamento de sedimentos, processos erosivos, surgimento de ravinas, assoreamento dos cursos d'água, entre outros problemas.

Essas características físicas não são favoráveis para que se estabeleça a urbanização, porém este fato deve-se a um processo histórico do município, acompanhado pela ausência de planejamento urbano na fase de expansão urbana da cidade de Ponta Grossa. 

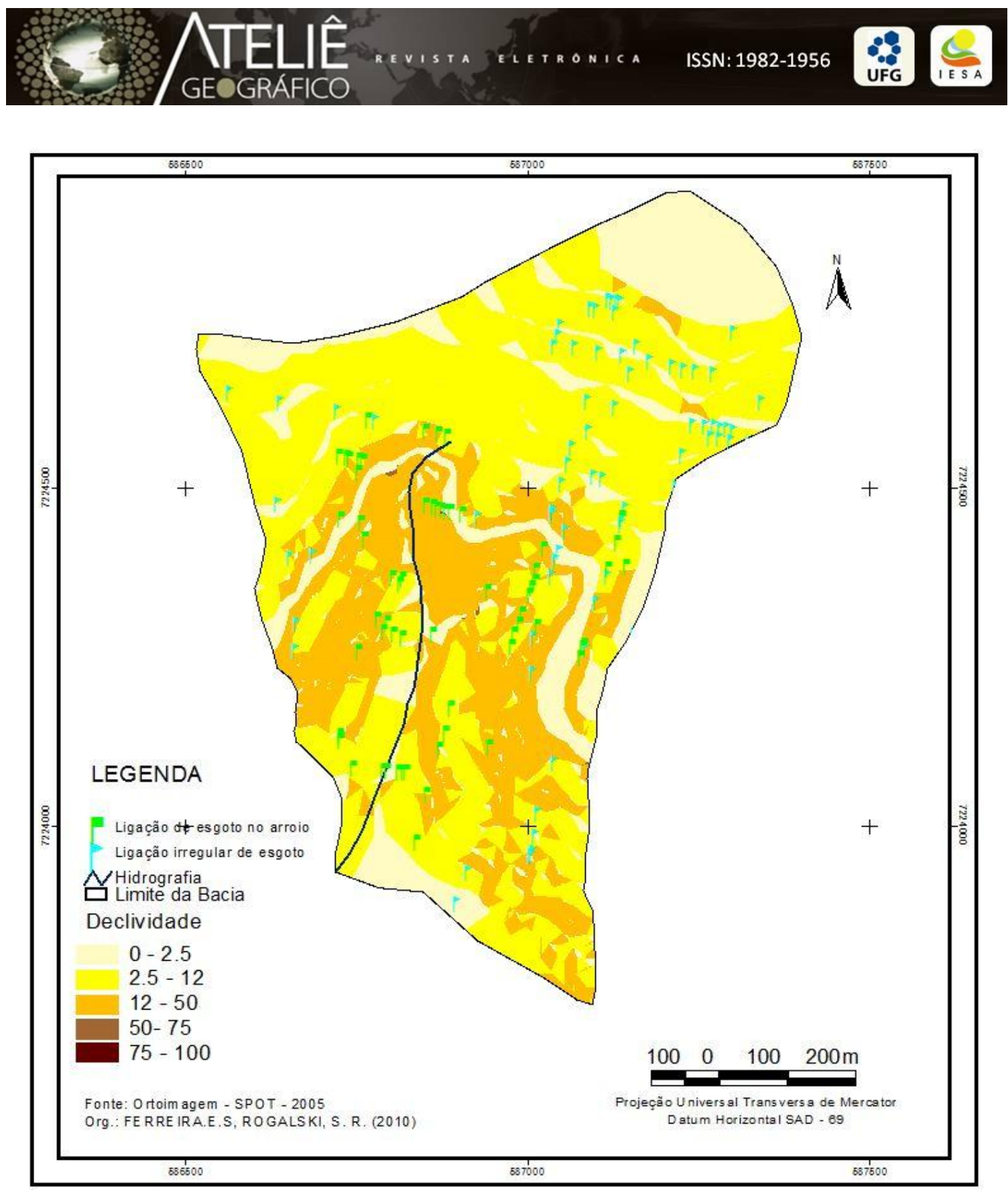

Figura 02 - Hipsometria da sub-bacia 02 do arroio Olarias.

Os resultados do Programa de Despoluição Ambiental apontaram duas áreas distintas, uma área com maior infra-estrutura urbana e oura área com menor infraestrutura urbana, o que permite fazer correlações no que refere-se à qualidade ambiental e urbana da área. 

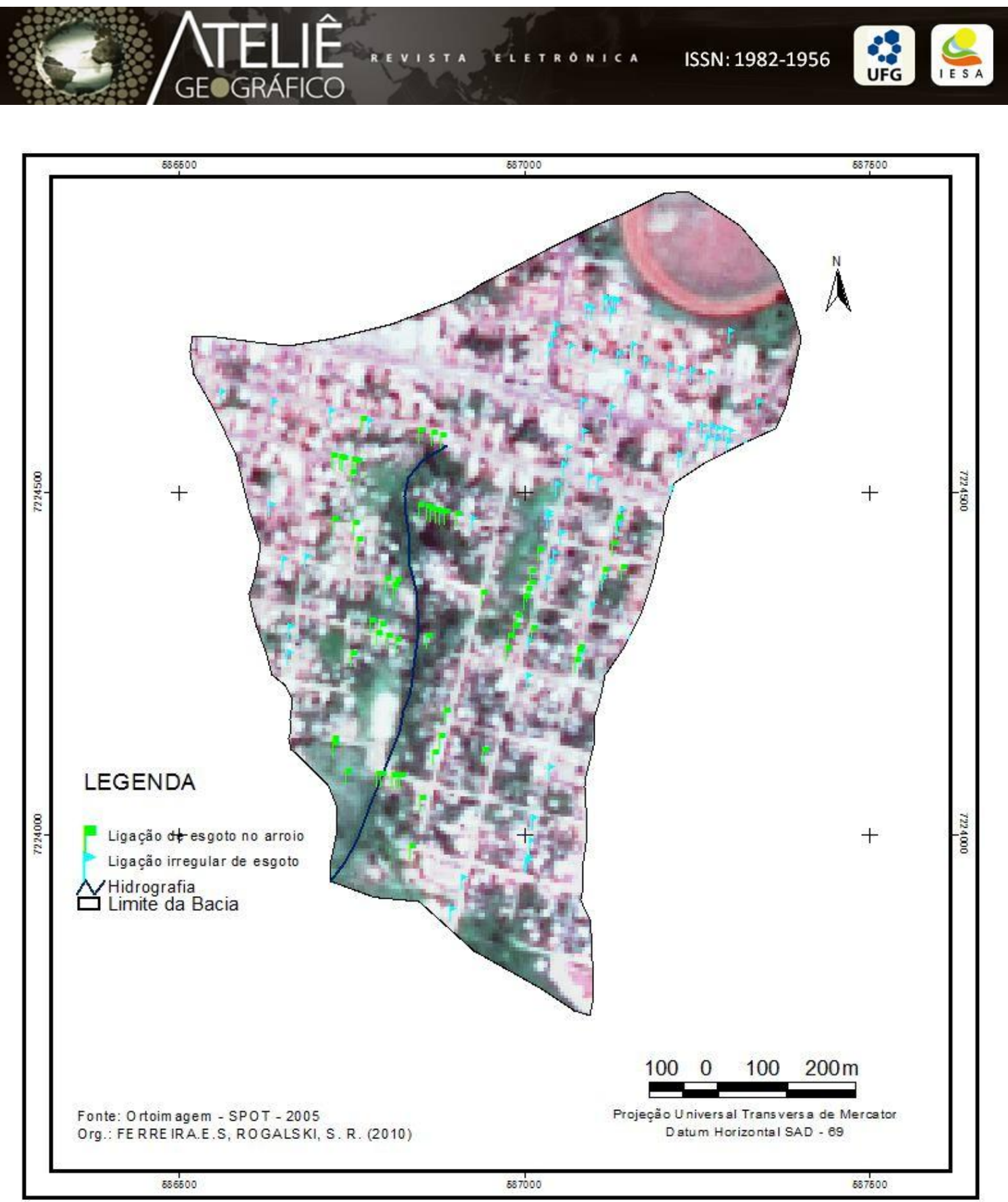

Figura 03 - Ligações irregulares de esgoto sub-bacia 02 do arroio Olarias.

A área com maior infra-estrutura urbana está compreendida na porção da cabeceira da sub-bacia 02 do arroio Olarias. Nessa porção encontra-se a menor parcela de imóveis com ligações na rede coletora de esgoto, além de apresentar parte das vias públicas com asfalto, coleta de lixo, telefone público, escola estadual, comércio e o eixo estruturante da Avenida General Carlos Cavalcanti, a principal via do bairro de Uvaranas ao centro comercial da cidade. As ligações irregulares de esgoto nessa porção são em galerias de águas pluviais onde a rede coletora de esgoto é fragmentada. Cabe destacar nessa discussão que a sub-bacia 02 encontra-se muito próxima do centro

Ateliê Geográfico Goiânia-GO v. 6,n. 2 ago/2012 $\quad$ p.75-94 Página 86


comercial da cidade e, entretanto, não possui o sistema coletor de esgoto. A concessionária SANEPAR justifica a não implantação do sistema coletor de esgoto devido à topografia local a qual dificulta e encarece a implantação do serviço.

A área com menor infra-estrutura urbana está compreendida na porção mais baixa da sub-bacia, cujos imóveis que apresentam ligações irregulares de esgoto estão em grande maioria em áreas de preservação permanente e lançam seus efluentes domésticos diretamente no arroio Olarias.

A grande maioria das vias públicas nessa área não possui asfalto, calçada, galerias de águas pluviais e rede coletora de esgoto. Uma pequena parcela das ruas não é contemplada pela coleta de lixo por causa do terreno íngreme e solo argiloso, o que impede o acesso da coleta. Desta forma, boa parte do lixo é despejada no arroio. Com isso, a relação lixo e arroio é um fator cultural, pois as famílias que residem nos fundos de vale vêem o arroio como um esgoto ao longo dos anos.

As ligações entre algumas ruas são precárias, ou seja, apenas por pontes rudimentares sem condições de segurança para a população local. A emissão de águas servidas diretamente nas vias públicas é comum em alguns trechos ocasionado mau cheiro. A falta de limpeza nas vias públicas desencadeia a proliferação de insetos e animais peçonhentos, segundo relatos dos moradores locais.

A instalação de fossas sépticas, mesmo que do tipo rudimentar, é considerado como quase inviável por boa parte da população. Isto ocorre somente após a notificação da Vigilância Sanitária e aplicação da legislação municipal. Cabe destacar que uma parcela significativa da população residente nessa área apresenta um perfil sócioeconômico muito baixo, sendo difícil ter as condições financeiras necessárias para regularização dessa situação.

Essas informações são relevantes para análise socioambiental da sub-bacia, entretanto é possível associar metodologias de diagnóstico ambiental permitindo maiores informações sobre a qualidade ambiental da área de estudo. Existem diversas metodologias possíveis de aplicação para o diagnóstico e mensuração da degradação ambiental tanto em ecossistemas como em bacias hidrográficas, uma vez que a abordagem socioambiental prevê estudos que integrem os fatores abióticos, bióticos e culturais de um determinado ambiente. 
A metodologia IDA emprega dados demográficos e oferece uma análise integrada dos elementos abióticos, bióticos e antrópicos de uma bacia hidrográfica. Através do mapa de vegetação, solo, declividade, uso e ocupação do solo e dados do IBGE sobre a densidade demográfica, por meio dos setores censitários da bacia hidrográfica permitem medir o grau de degradação ambiental. A sub-bacia 02 apresentou três classes de qualidade ambiental conforme a figura 04 .

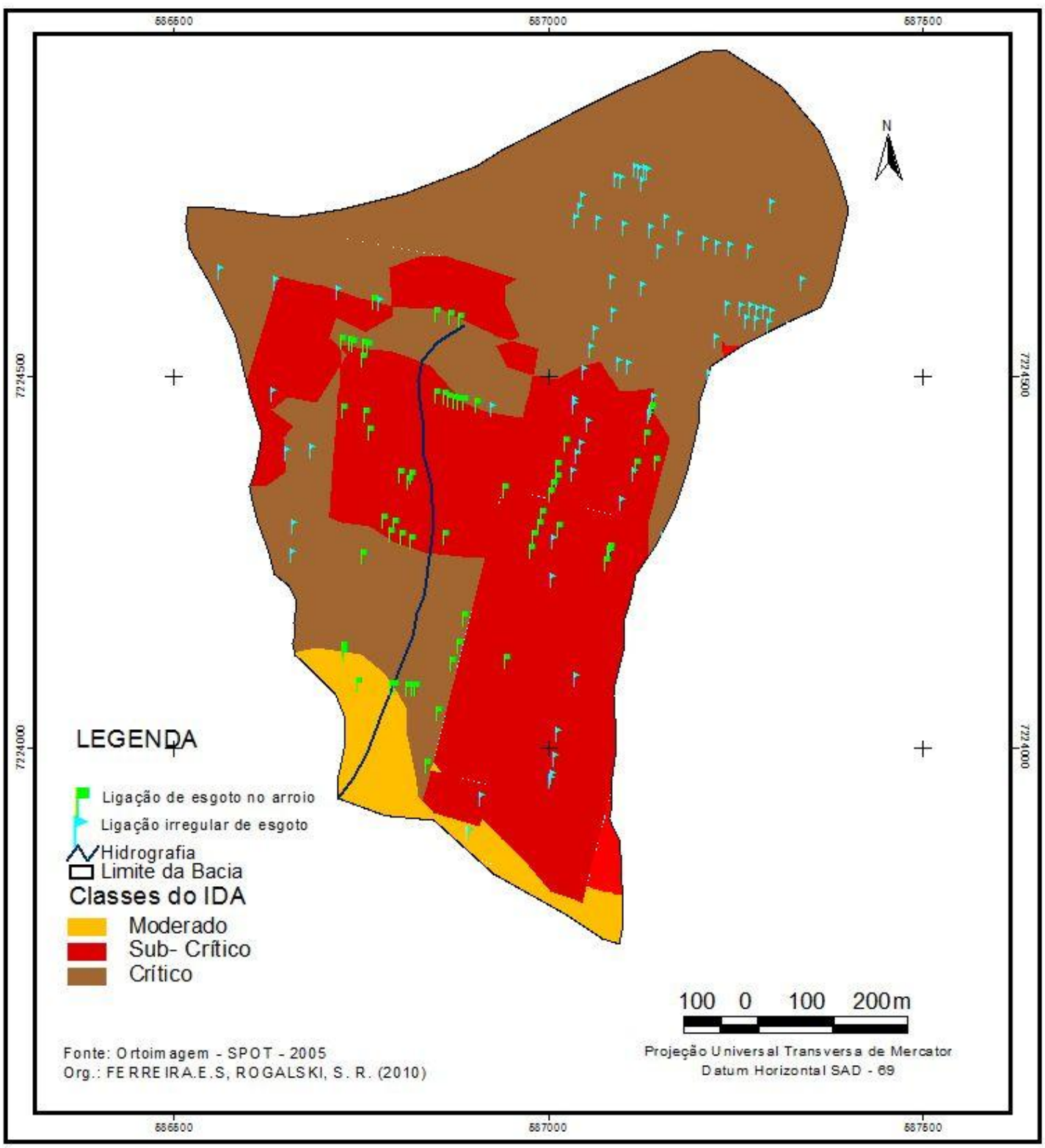

Figura 04 - Índice de degradação ambiental da sub-bacia 02 do arroio Olarias. 
A classe qualidade ambiental crítica foi a mais representativa, principalmente nas cabeceiras, onde os solos encontrados são classificados como latossolos, a metodologia IDA, aponta que áreas com esse tipo de solos é mais expressivo para degradação ambiental, quando associado com ausência de cobertura vegetal nativa, declividade acentuada e pressão antrópica elevada.

A classe ambiental sub-crítica é mais representativa na porção médio-inferior da sub-bacia, onde encontra-se os solos cambissolos. Conforme a metodologia IDA, solos do tipo cambissolos são menos expressivos para degradação ambiental, porém a subbacia apresentou uma pequena parcela de vegetação nativa associado com declividade acentuada e a pressão antrópica elevada torna-se essa área degradada.

A classe ambiental moderada representa uma pequena área da sub-bacia onde estão compreendidas as áreas de preservação permanente, cuja vegetação é nativa, com declividades menos elevadas com solos classificados como cambissolos.

Além dessas informações do ambiente físico e metodologia de diagnóstico ambiental, também foram realizadas análises da qualidade da água segundo a Resolução CONAMA $\mathrm{N}^{\mathrm{o}}$. $357 \mathrm{em}$ seis pontos estratégicos. As coletas de água bem como a definição dos pontos foram feitas pela ARAS e a análise da água, realizada pela SANEPAR. O objetivo dessa análise foi verificar o grau de poluição do arroio caso fosse criado à represa do lago Olarias, na porção média do arroio, para criação de um parque linear e urbanístico.

As análises de água realizadas pela ARAS na bacia do arroio Olarias apontam que a maior degradação em relação à qualidade da água ocorre nas cabeceiras, conforme Resolução do CONAMA, Nº 357 de 15 de março de 2005. De acordo com os parâmetros da referida resolução, as águas do arroio Olarias classificam-se como classe 4: ou seja, a água tem uso restrito para à navegação e harmonia paisagística.

Discutindo a correlação dos dados encontrados e os definidos pela resolução para a classe 4, essa situação de degradação da qualidade da água deve-se, entre outras situações, ao estado atual da coleta e tratamento de efluentes domésticos como bem demonstra a figura abaixo . 


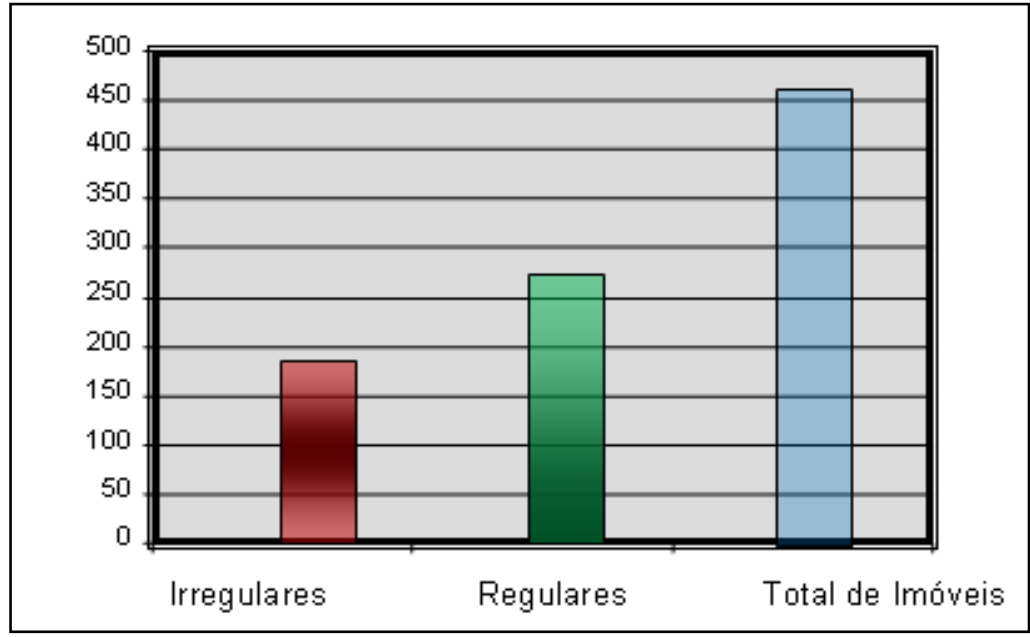

Figura 05 - Distribuição da coleta de efluentes domésticos em relação ao total de imóveis.

Fonte: ARAS. Maio/2008. Org.: Rogalski, (2008).

A sub-bacia 02 apresenta 462 imóveis cuja distribuição das ligações é expressa por 274 fossas rudimentares, as quais são consideradas regulares pelo PDA, porém podem contaminar o lençol freático, uma vez que essa área apresenta solo do tipo cambissolo, o qual apresentam pouca profundidade com grande permeabilidade e pode apresentar problemas de contaminação do lençol freático. Apresentam também 102 ligações diretas no arroio, 86 ligações em galerias de águas pluviais. Cabe destacar que deste mesmo total de imóveis apenas 3\% (15 imóveis) estão conectadas à rede coletora de esgoto da concessionária local.

\section{Considerações finais}

A infra-estrutura urbana depende de algumas variáveis que, podem afetar direta ou indiretamente a qualidade de vida, bem como o meio. Então, urge a atuação de bons planejadores e gestores urbanos para que tais variáveis sejam consideradas.

O município de Ponta Grossa, neste caso, apresenta um relevo significativamente acidentado, afetando e dificultando assim, uma integração espacial urbana. Associado a este fator de ordem físico-natural, ocorre o processo das ocupações irregulares, principalmente em áreas consideradas de risco, tais como: terrenos com alta 
declividade, áreas com risco de inundação, áreas de proteção ambiental (margens de córregos, reservas verdes).

Em parte, em decorrência dessa peculiaridade topográfica, a implantação do sistema de coleta e tratamento de esgoto do município de Ponta Grossa tem acontecido de forma pulverizada, seja pela inviabilidade técnica da execução da obra, seja pelo encarecimento da mesma. Sendo assim, a rede coletora de esgoto não se deu de forma homogênea, não contemplando assim algumas vilas nessa infraestrutura, como o caso da área do presente estudo.

Nesta pesquisa pode-se observar que, além da questão infraestrutural urbana, outros aspectos de ordem socioambiental - como as condições de moradia, os resíduos sólidos (lixo), a poluição do arroio, a presença de áreas sob riscos geoambientais, devem ser interpretados e analisados como forma de apontar soluções possíveis na diminuição desses problemas.

Em campo, na sub-bacia 02, identificaram-se as ligações irregulares de esgoto, normalmente lançadas em galerias de águas pluviais e ou diretamente no canal fluvial mais próximo. Essa observação mostrou que o número de irregularidades em relação ao esgotamento sanitário é muito elevado, chegando a 41\%, para as 462 visitas realizadas pelo PDA. Isto aponta a falta de fiscalização e de regularização por parte dos gestores públicos ao longo de muitas décadas, pois essa população está instalada na área há muitos anos. Cabe destacar que além da degradação ambiental encontrada na sub-bacia 02, as sub-bacias 01, 03 e 04 também não possuem rede coletora de esgoto, o que justifica a gestão pública municipal a não implantação do lago Olarias.

Urge a proposição de políticas públicas e também a implementação de ações educativas para mitigar esses problemas. Cabe, antes de tudo, articular e desenvolver uma gestão integrada com outros órgãos e secretarias municipais e estaduais, envolvendo a iniciativa privada, sociedade civil e as escolas.

A criação da Agência Reguladora de Águas e Saneamento Básico aparece como um passo importante no sentido de proporcionar um processo de apoio às populações marginalizadas e buscar o tão almejado desenvolvimento urbano mais sustentável.

Apesar da concessionária estadual - a SANEPAR - contemplar $88 \%$ da rede coletora de esgoto e tratamento dos mesmos do município, faz-se necessário a participação de outros órgãos, instrumentos e mecanismos que viabilizem atingir os 
$100 \%$ de atendimento do saneamento urbano, conforme preceito da lei 9.433/97, a qual dispõe sobre a gestão integrada dos recursos hídricos. A ARAS foi criada com esse objetivo - atuar em parceria com a SANEPAR e demais órgãos e entidades que se ocupam dessas questões tão relevantes.

Os subsídios que os órgãos e as instituições públicas necessitam para mudar o atual quadro são oferecidos pelos recursos das Geotecnologias. A proposta é que esses instrumentos e geotecnologias forneçam os dados e informações atualizadas e de fácil leitura e manuseio, pois podem se tornar subsídios técnicos à implementação de planejamento que vise à gestão ambiental e dos recursos hídricos do município.

Ao definir a bacia hidrográfica enquanto unidade de gestão faz-se necessário à elaboração de plano diretor de recursos hídricos, uma vez que o município de Ponta Grossa, assim como outros tantos no estado, não possui um instrumento de planejamento das bacias hidrográficas.

Faz-se necessário destacar que esse trabalho possibilitou a extensão da rede coletora de esgoto em parte da sub-bacia 02 . No entanto, essa sub-bacia ainda apresenta diversos problemas socioambientais, de difícil resolução pelo poder público, pois as políticas municipais ainda não são totalmente integradas e suficientes para gestão ambiental em bacias hidrográficas urbanas.

\section{Referências bibliográficas}

AGÊNCIA REGULADORA DE ÁGUAS E SANEAMENTO BÁSICO DE PONTA GROSSA - ARAS. Dados do Programa de Despoluição Ambiental. 2008.

BRANDÃO, Marcelo, Melo, Henrique de. Índice de Degradação Ambiental na Bacia Hidrográfica do Rio do Peixe - PB. Pernambuco, p. 110, 2005. Tese de Doutorado. Pós-Graduação em Geografia, área de concentração: Geologia Sedimentar e Ambiental. Universidade Federal de Pernambuco.

BRASIL. Lei n. ${ }^{\circ} 11.445,05$ de janeiro de 2007. Estabelece diretrizes gerais nacionais para o saneamento básico. Disponível em:

<http://www.planalto.gov.br/ccivil_03/_ato2007-2010/2007/lei/111445.htm>. Acesso em: 20 jul. 2008.

CARVALHO, M. S. O Diagnóstico Físico-Conservacionista - DFC como subsídio à Gestão Ambiental da Bacia Hidrográfica do Rio Quebra-Perna, Ponta Grossa - 
PR. Presidente Prudente, 2004. Tese de Doutorado. Pós-Graduação em Geografia, área de concentração: Produção do Espaço Geográfico. Universidade Estadual Paulista.

COMPANIA DE SANEAMENTO DO PARANÁ - SANEPAR. Matrículas de residências cadastradas na SANEPAR. 2008.

CONAMA. Conselho Nacional do Meio Ambiente - dispõe sobre a classificação dos corpos de água. Disponível em: www.mma.gov.br/port/conama/legiano. Consultado em 11 de setembro de 2008.

DIEDRICHS, L. A. Os problemas ambientais e a urbanização da bacia hidrográfica do arroio Olarias - Ponta Grossa/PR. Curitiba: 2001. Dissertação de Mestrado. PósGraduação em Geografia, área de Concentração Produção do Espaço Urbano e regional, Setor de Ciências da Terra. Universidade Federal do Paraná.

FRANKIEVICZ, M. S. Caracterização Geoecológica da paisagem da vila Jardim Los Angeles, Ponta Grossa-PR: um olhar aos processos geomorfológicos. 2008. Trabalho de Conclusão de Curso (Graduação em Licenciatura em Geografia) Universidade Estadual de Ponta Grossa.

INPE. Curso de sensoriamento remoto aplicado ao zoneamento ecológicoeconômico. São José dos Campos: INPE, 1996. 18p. (INPE-6145 - PUD/028).

MELO, M.S.; GODOY, L.C. Geologia, Geomorfologia e riscos geológicos na bacia do arroio Olarias, Ponta Grossa, PR. Publicado UEPG, Ponta Grossa, v. 3, n 1, p. 3359, 1997.

MENDONÇA, F. Geografia sócio-ambiental. São Paulo, Terra Livre; n. 16, 2001.

NUCLEAM. NÚCLEO DE ESTUDOS EM MEIO AMBIENTE. Planejamento Ambiental da Bacia do Arroio de Olarias. Ponta Grossa, 2001.

PEREIRA, M. A. Diagnóstico Físico e Socioambiental do Parque municipal da Lagoa do Peri: Subsídios ao Plano de Manejo. 2001. 243f. Dissertação (Mestrado e Geografia). Departamento de Geociências, UFSC, Florianópolis.

PRODES. Programa de Despoluição Ambiental. Dispõe sobre os parâmetros da gestão de Bacias Hidrográficas Brasileiras. Disponível em <http//: www.ana.gov.br/prodes> Acesso: em 05 de setembro de 2008. 
ROGALSKI, S. R.; CARVALHO, S. M. Análise do programa de despoluição ambiental da bacia hidrográfica do Arroio Olarias do município de Ponta Grossa PR. Londrina, Geografia, v. 19, n.3, 2010.

ROSS, J. L. Análise empírica da fragilidade dos ambientes naturais e antropizados. In: Revista do departamento de geografia n. ${ }^{\circ}$ 05, FFLCH-USP, São Paulo, 1994.

STRAHLER, A. N. Quantitative analysis of watershed geomorphology. Trans. Am. Geophys. Un., v. 38, p. 913-920, 1957.

Recebido para publicação em setembro de 2011 Aprovado para publicação em novembro de 2011 